\title{
Combining experimental evidence with machine learning to assess anti-corruption educational campaigns among Russian university students
}

\author{
Elena Denisova-Schmidt ${ }^{1,4}$ (D) Martin Huber ${ }^{2}$ Elvira Leontyeva ${ }^{3}$. \\ Anna Solovyeva ${ }^{2}$
}

Received: 25 January 2019 / Accepted: 27 January 2020

c) Springer-Verlag GmbH Germany, part of Springer Nature 2020

\begin{abstract}
This paper examines how anti-corruption educational campaigns affect the attitudes of Russian university students toward corruption and academic integrity in the short run. About 2000 survey participants were randomly assigned to one of four different information materials (brochures or videos) about the negative consequences of corruption or to a control group. While we do not find important effects in the full sample, applying machine learning methods for detecting effect heterogeneity suggests that some subgroups of students might react to the same information differently, albeit statistical significance mostly vanishes when accounting for multiple hypotheses testing. Taking the point estimates at face value, students who commonly plagiarize appear to develop stronger negative attitudes toward corruption in the aftermath of our intervention. Unexpectedly, some information materials seem inducing more tolerant views on corruption among those who plagiarize less frequently and in the group of male students, while the effects on female students are generally close to zero. Therefore, policy makers aiming to implement anti-corruption education at a larger scale should scrutinize the possibility of (undesired) heterogeneous effects across student groups.
\end{abstract}

Keywords Anti-corruption campaigns · Experiments · Corruption · Academic integrity $\cdot$ University $\cdot$ Students $\cdot$ Russia

JEL Classification D73 · I23 · C93

The authors are thankful to participants of IX International Russian Higher Education Conference (RHEC), 2018, Moscow, for their feedback.

Electronic supplementary material The online version of this article (https://doi.org/10.1007/s00181020-01827-1) contains supplementary material, which is available to authorized users.

$凶$ Elena Denisova-Schmidt

elena.denisova-schmidt@unisg.ch

Extended author information available on the last page of the article

Published online: 05 February 2020 


\section{Introduction}

Young people — and particularly students — are frequently observed to be the driving forces pushing for reforms that promote justice and fight corruption. The Rose Revolution in Georgia (2003), the Tulip Revolution in Kyrgyzstan (2005), the Arab Spring in Egypt (2011) and the student movements in Taiwan (2014) and Hong Kong (2016), as well as the protests against corruption in Bulgaria (2013), Ukraine (2014), and Romania (2017), are a few recent examples of student activism that resulted in social change (Altbach 2016; Cantoni et al. 2019; Denisova-Schmidt et al. 2015; Klemenčič 2014). In Russia, where the Putin generation is often viewed as infantile and apolitical (Kasamara and Sorokina 2017; Volkov 2017), the recently increased participation of youth in anti-corruption rallies is particularly interesting and controversial.

Corruption ${ }^{1}$ has received substantial attention in Russia over the last decade. This is not only because of its detrimental effects on the national economy and society in general, but also because it became increasingly politicized. The Russian opposition movement has built an agenda around it, attracting a growing number of supporters, among them many high school and university students. Public anti-corruption rallies in March 2017 were even described as "angry pupils' walks" in the media (Korostelev et al. 2017). On the other hand, opinion polls suggest that active participants in anticorruption rallies are not representative for the Russian youth. According to Volkov (2017), less than 8\% of those aged 18-24 have an interest in political issues and discuss them with friends or relatives, while only about $10 \%$ in this age-group are ready to protest. Overall, the stance of the Russian youth toward corruption issues is not clear, as no comprehensive study has yet scrutinized this problem on a grand scale.

This paper (a) investigates the views of public university students in the Russian region of Khabarovsk on corruption and academic dishonesty during their studies and (b) examines the short term effects of an educational campaign exposing students to various informational materials about corruption and its negative consequences. To this end, we surveyed a sample of about 2000 students and examined four different anticorruption materials: two videos produced by Transparency International Russia about the negative consequences of bribery and reiderstvo (a hostile corporate takeover), a general anti-corruption brochure developed by the local authorities, and a brochure addressing local corruption cases developed by the authors for students.

The results of our study suggest that various forms of academic cheating (e.g., plagiarizing written work or copying from others during exams) are quite common at Russian universities. At the same time, corruption is predominantly viewed as something bad- "crime" and "evil" are the strongest associations expressed in the survey. The perception of corruption at the national level is more negative than at the individual level, which points to the possibility that some respondents have adapted to the situation and might use it for their own benefit. Interest in a round table discussion about corruption - a proxy for inclination toward anti-corruption activities-is strikingly low: Only 5\% of students agreed to join this event. This might be suggestive for young participants in anti-corruption rallies not being representative for the majority

\footnotetext{
1 Corruption can be defined as both "the abuse of entrusted power for private gain" (Transparency International) and "the lack of academic integrity"; see recent discussions with examples in Denisova-Schmidt (2017, 2019) and Denisova-Schmidt and de Wit (2017).
} 
of Russian students, which would also be in line with statistics showing low political activism among the youth (Volkov 2017).

Concerning the effectiveness of the interventions, we do not find any important impacts in the full sample, but some indication of heterogeneous effects across subsamples defined by students' inclination to plagiarize when writing papers. One result is that some of the brochures or videos might promote awareness of the negative consequences of corruption among students who frequently plagiarize, but at the same time appear to induce more tolerant views on corruption among students who plagiarize less often. We also consider gender differences and find that female students appear to have stronger negative attitudes toward corruption, ${ }^{2}$ but to be generally less responsive to interventions and more reluctant to participate in anti-corruption activities than males. We emphasize that our findings on effect heterogeneity need to be interpreted with caution, as statistical significance mostly vanishes when accounting for multiple hypothesis testing. ${ }^{3}$

Our paper is among a growing number of corruption studies using laboratory or field experiments for causal inference (see for example Armantier and Boly 2011, 2013; Barr and Serra 2010; Findley et al. 2014; Holmes 2015; Serra and Wantchekon 2012). In particular, our study is related to Denisova-Schmidt et al. (2015, 2016), which investigate the effectiveness of an anti-corruption folder developed by Transparency International among students in Ukraine and Russia, respectively. Similar to our comparison of less and more plagiarizing students, Denisova-Schmidt et al. (2015) separately consider students with and without experience in corrupt activities and also find that the intervention might increase tolerance for corrupt behavior. We improve upon these previous studies by considering more and different interventions (both brochures and videos) and a larger sample. As a methodological advancement, we use machine learning approaches by Belloni et al. (2014), Athey and Imbens (2016), and Ludwig et al. (2017) for conducting robustness checks, finding effect heterogeneities, and accounting for multiple hypothesis testing, respectively. ${ }^{4}$ John et al. (2014) conduct an experiment with task performance among US students and find that the awareness that others realize higher pay rates for comparable tasks increases dishonesty, likely due to fairness concerns about pay-rate differentials. In the same vein, Corbacho et al. (2016) find for an information experiment in Costa Rica that

\footnotetext{
2 A large body of empirical literature suggests that women tend to be less corrupt; see Dimant and Tosato (2017), Dollar et al. (2001), Frank et al. (2011), Rivas (2013) and Swamy et al. (2001).

3 See, for instance, Romano and Wolf (2005, 2016), Lehrer et al. (2016), and Ludwig et al. (2017) for inference methods that account or correct for multiple hypothesis testing.

4 Alternatively, issues of multiple hypothesis testing could have been addressed by means of a pre-analysis plan outlining the methodology to be used for analyzing the data prior to collecting them, see for instance Nosek et al. (2018) for an in-depth discussion. A pre-analysis plan typically pre-specifies the hypotheses to be tested in a detailed way and includes a power calculation to determine the sample size required to detect effects with a specific probability. Such pre-registration prevents ex post snooping for statistically significant effects across outcomes or groups that have not been declared in the plan. Currie et al. (2019) demonstrate that even though discussions of pre-analysis plans are still rare in economics, they have been increasing sharply since 2012, after the American Economics Association decided to provide a registry for such plans. We acknowledge that no pre-registration was conducted for this study and for this reason, we apply specific machine learning methods to mitigate the issue of multiple hypothesis testing.
} 
informing individuals about the commonness of corruption increases their inclination to bribe.

Relating these results to a theoretical perspective, Corbacho et al. (2016) argue that there are broadly speaking two theoretical views of an individual's choice to engage in or abstain from corrupt activities. The first one is decision-theoretic and postulates that individuals evaluate the expected benefits and (opportunity) costs of corrupt behavior, e.g., as a function of moral judgments and the institutional context (as the likelihood of detection or punishment). The second one is game-theoretic in the sense that an individual's decision also strategically hinges on beliefs about the behavior of others, as the expected return associated with corruption is increasing in the expected number of corrupt actors. This implies as strong incentive for coordination of engaging in or abstaining from corruption in a society. According to Corbacho et al. (2016), coordination dilemmas and herd behavior are important factors driving corruption in the game-theoretic perspective, entailing a high correlation of corruption levels over time. The authors list among the (many) possible mechanisms underlying this phenomenon search costs (with costs decreasing in the perceived corruptibility of others), guilt aversion when engaging in corruption (with guilt decreasing in the commonness of corruption), and imitation. Along with the fairness concerns raised in John et al. (2014), these mechanisms might make information interventions about the commonness of corruption increase its acceptance among specific groups, as suggested by several empirical findings. On the other hand, such interventions might nudge moral judgment into the intended direction and thus decrease the acceptance of corruption, such that the net effects might differ across individuals.

The remainder of this paper is organized as follows: Section 2 explains the research design and presents the data along with descriptive statistics. Section 3 discusses the estimation methods applied, while Sect. 4 reports the results. Section 5 concludes.

\section{Research design and data}

Our study is based on a randomized information campaign conducted among university students in two cities of the Khabarovsk region-Khabarovsk and Komsomolsk-onAmur. With populations of about 611,000 and 251,000 people (as of January 1, 2016; Federal State Statistics Service, 2016), respectively, both cities are among the largest urban centers in the Russian Far East. There are 12 universities in Khabarovsk and two in Komsomolsk-on-Amur, with a total of around 68,700 students in the Khabarovsk region in 2015 (Obrazovanie v Rossiiskoi Federatsii 2014).

The sample of students was drawn from four large public universities in Khabarovsk and two in Komsomolsk-on-Amur, whose total student population accounted for over $70 \%$ of all students in the region in 2016 (according to our own calculations based on online enrollment data from the participating universities). The survey was conducted in November and early December 2016 by a group of students previously instructed by our research team using the following research design: interviewers approached students on campuses asking questions about their major, year and education scheme (full- or part-time, on-site, or distance education). Only full-time, on-site students with majors in social sciences, natural sciences, engineering, or humanities were selected for 
the study. First-semester bachelor and diploma students were excluded, as they could lack sufficient experience and knowledge about university life. Students in other disciplines, e.g., medicine or theology, were not selected because of their small program sizes. Eligible individuals were asked to take part in a survey about attitudes toward corruption. The questionnaire included a range of questions about the students' motivation to join the university, their academic performance, previous experiences with informal practices, ${ }^{5}$ family background, and several demographic and socioeconomic characteristics. All interviews were conducted face-to-face and the interviewers filled out the questionnaire forms in Russian, the native language of all the persons involved. ${ }^{6}$

At one point during the interview, namely before being asked about their attitudes toward corruption and informal practices, participants were randomized into one of the four interventions, henceforth also referred to as treatments, or a control group. Each treatment included exposure to one type of information materials about corruption and its negative consequences. To this end, the interviewer asked students to roll a fair six-sided (cubical) die, with the treatment depending on the outcome. If 1 was rolled, the student received an official corruption-awareness brochure (henceforth called the "official brochure"). Rolling a 2 entailed a brochure prepared by our research team on the basis of the materials by Transparency International, a global anti-corruption NGO, and tailored to the student audience (henceforth called the "tailored brochure"). For a 3 or 4, a short video by Transparency International Russia about the negative consequences of bribery or about hostile corporate takeovers ("reiderstvo"), respectively, was shown. Rolling 5 and 6 entailed assignment to the control (or non-treated) group, in which no treatment was provided prior to continuing the interview. The brochures were professionally printed and the video materials were shown on tablets brought along by the interviewers.

The official brochure was, in our opinion, overwhelming for readers, as it contained very detailed information, as well as long, redundant definitions, and it was pedantically written and typed in a very small font. It included a portrait of the Russian president Vladimir Putin and his quotation about the fight against corruption, long definitions of corruption and anti-corruption activities, and a list of laws and directives against corruption. It also contained some corruption-related statistics, examples of anti-corruption measures in the Khabarovsk region, an enumeration of punishments for corruption-related crimes, and a long list of contact information of various responsible authorities (see Online Appendix B for the brochure translations).

The tailored brochure was created by our research team with students in mind. We provided succinct and practical information, knowing the survey participants would lack the time and focus to absorb less important details. Simple, everyday language was preferred over complex official formulations. The tailored brochure contained a short definition of corruption, a graph describing different types of corruption, some statistics, the negative consequences of bribery (a common corruption type), examples of recent corruption crimes in the Khabarovsk region, and a call for action.

\footnotetext{
5 Here, "informal practices" refers to the practical norms that people often use in order to get things done.

6 Two sensitive questions about the students' application of informal practices in their studies and students' experience with bribery at the university were asked on a separate card and filled out by the interviewees themselves.
} 
The videos about the negative consequences of bribery and hostile corporate raiding were part of the "Ten Faces of Corruption" cartoon series developed by Transparency International Russia within the educational project "The Alphabet of a Corruption Fighter". The project targeted high school and university students and attempted to clarify basic corruption-related concepts. The cartoons only offered video content without audio commentary. The characters were rats depicting the essence of various corrupt behaviors. The video about bribery (Transparency International Russia 2015a) featured a suicide bomber rat giving a bribe to a security officer when boarding an airplane. The bomb then exploded in the air destroying the plane. The video about reiderstvo (Transparency International Russia 2015b) showed rat police removing and arresting the director of a well-functioning cheese factory and overtaking his position. ${ }^{7}$

After the individuals assigned to the treatment groups had been exposed to the respective information materials, the interviewers continued with questions about informal academic practices used by students, their moral assessment of corruption, and whether corruption could be eradicated in Russia. At the end of the interview, students were invited to participate in a round table discussion taking place on International Anti-Corruption Day $^{8}$ (December 9, 2016) at the Pacific National University in Khabarovsk and were asked whether they would be willing to participate. Finally, respondents were asked whether they would take part in a similar survey next year. Interested students could leave their contact information. All of these post-intervention questions were used to construct outcome variables.

Despite the aim to randomize treatment assignment by rolling a die, the distribution of numbers 1 to 6 in the full sample is not perfectly uniform, as illustrated in Fig. 1. In fact, Pearson's Chi-squared test clearly rejects the uniform distribution at the 5\% level of statistical significance. ${ }^{9}$ The probabilities of the brochure treatments (treatments 1 and 2 in Fig. 1) were higher compared to the video treatments ( 3 and 4 ) and the control group (5 and 6).

Despite such imbalances in treatment assignment, the average values of the covariates measured in the survey prior to treatment are balanced across the treatment states similarly to a successfully randomized experiment. $F$-tests conducted for each of the 87 observed covariates revealed hardly any statistically significant (at the 5\% level) differences across treatment groups; see Table A1 in Online Appendix A. One exception was the indicator for living with both parents with a $p$ value of 0.04 . For four further covariates - namely, the indicators for living without parents, father's occupation: homemaker or a retiree, having a Unified State Exam (USE) score of more than 250 (highest quantile), and having a job related to students' education-differences were statistically significant at the $10 \%$ level. Given the large number of covariates tested, we are not concerned by these few rejections. Nevertheless, as a robustness check, we ran the main estimations presented in Sect. 4 on the subsample of students surveyed by the interviewers for whom proper treatment randomization (i.e., uniformly distributed numbers 1 to 6 ) could not be rejected at the $10 \%$ level when conducting

\footnotetext{
7 Reiderstvo, or asset-grabbing, is the illicit acquisition of a business or part of a business in Russia.

8 The General Assembly of the United Nations introduced Anti-Corruption Day in 2005 in order "to raise awareness of corruption and of the role of the Convention [against Corruption, resolution 58/4] in combating and preventing it" http://www.un.org/en/events/anticorruptionday/background.shtml.

9 The test statistic and the critical value are equal to 21.08 and 9.24 , respectively.
} 


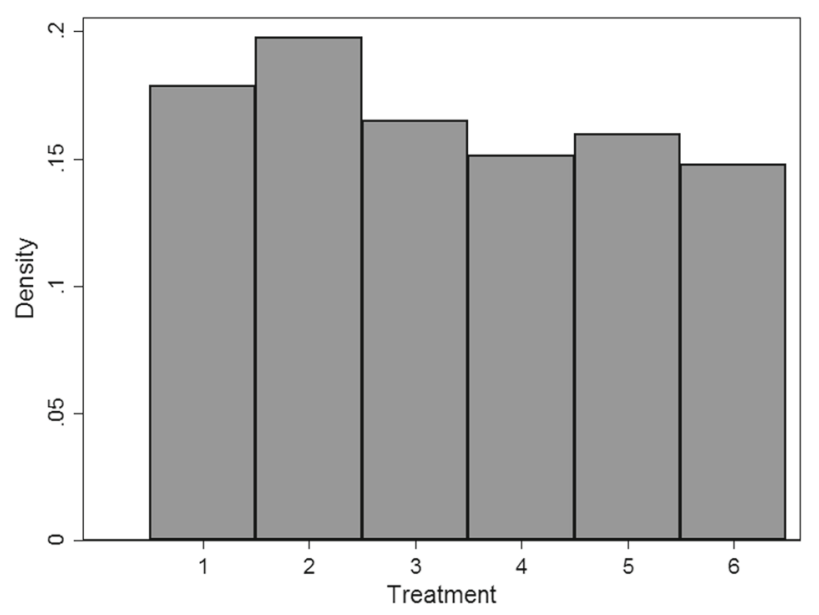

Fig. 1 Treatment distribution in the full sample

$F$-tests separately for each interviewer. Neither covariate balance nor treatment effect estimates in this subsample differed to an important extent from our main results based on the full sample.

Our evaluation sample consists of 2003 individuals, 75\% (1501) studying in Khabarovsk and 25\% (502) in Komsomolsk-on-Amur. Table 1 shows the means and the standard deviations for selected covariates ${ }^{10}$ for the 1741 respondents without any missing values in these variables. The typical respondent is about 20 years old and just over half of the sample (54\%) is female. About one-third of the individuals report to spend on average less than 10,000 rubles (USD 155) ${ }^{11}$ a month, while $55 \%$ of the respondents have average monthly expenditures between 10,000 and 20,000 rubles (USD 155-310), and 12\% spend more than 20,000 rubles. The university education of slightly more than half of the students is state-financed. About $37 \%$ of the survey participants study humanities, $31 \%$ social sciences, $25 \%$ technical sciences, and $8 \%$ natural sciences.

Concerning previous experiences with wrongdoing and corruption, the selfassessed use of connections is more common than bribery for solving problems. Yet the incidence of additional payments in school prior to tertiary education (e.g., fees for construction, maintenance and school repairs, guarding, etc.) is non-negligible and higher than gift-giving to teachers. ${ }^{12}$ Strikingly, about $34 \%$ of the participants claim to have encountered forms of wrongdoing (e.g., bribes, gifts, and help from on-site

\footnotetext{
10 The full list of covariates is given in Table A1 in Online Appendix A.

11 Based on the average of daily exchange rates from the Russian Central Bank in the period January 1 to November 1, 2016.

12 Primary and secondary education is predominantly public and tuition-free in Russia. However, informal payments at schools are widespread and range from covering basic maintenance of a school building and the provision of school guarding to some excessive school needs. While voluntary additional school payments have been ruled legal, the fees are often coercive in reality. Also, gift-giving to teachers can be voluntary or forced by parental committees or even the teachers themselves. Our data do not allow distinguishing between the two types in both the cases of additional school fees and gift-giving to teachers.
} 
Table 1 Summary statistics for selected covariates

\begin{tabular}{|c|c|c|}
\hline Variables & Mean & SD \\
\hline Age & 19.99 & 1.23 \\
\hline Gender: female (binary) & 0.54 & 0.50 \\
\hline Monthly spending: <10k rub (binary) & 0.33 & 0.47 \\
\hline Monthly spending: 10-20k rub (binary) & 0.55 & 0.50 \\
\hline Monthly spending: >20k rub (binary) & 0.12 & 0.33 \\
\hline Education is state-financed (binary) & 0.53 & 0.50 \\
\hline Major: humanities (binary) & 0.37 & 0.48 \\
\hline Major: social sciences (binary) & 0.31 & 0.46 \\
\hline Major: technical sciences (binary) & 0.25 & 0.43 \\
\hline Major: natural sciences (binary) & 0.08 & 0.27 \\
\hline Average grade $(1=$ satisfactory $\ldots 5=$ excellent $)$ & 3.26 & 1.12 \\
\hline Family or friends solved problems using connections $(1=$ never $\ldots 5=$ systematically $)$ & 2.34 & 1.04 \\
\hline Family or friends solved problems using bribes $(1=$ never $\ldots 5=$ systematically $)$ & 1.92 & 0.98 \\
\hline Frequency of giving gifts to teachers at school $(1=$ never $\ldots 5=$ systematically $)$ & 2.80 & 1.08 \\
\hline Frequency of paying additional fees at school $(1=$ never $\ldots .5=$ systematically $)$ & 3.22 & 1.20 \\
\hline Encountered (personally/friends/relatives) wrongdoing at USE (binary) & 0.34 & 0.47 \\
\hline Encountered (personally/friends/relatives) wrongdoing at univ.admission (binary) & 0.21 & 0.41 \\
\hline Encountered bribery at university $(1=$ never $\ldots .5=$ systematically $)$ & 1.55 & 0.86 \\
\hline \multicolumn{3}{|l|}{ How often do you use the following practices? $(1=$ never $\ldots 5=$ systematically $)$} \\
\hline Use cheat sheets at exams & 2.90 & 1.17 \\
\hline Submit papers downloaded from the internet & 2.25 & 1.26 \\
\hline Buy papers from friends or specialized firms & 1.85 & 1.15 \\
\hline Write papers plagiarizing some chapters from the internet & 3.27 & 1.20 \\
\hline Copy from other students during exams or tests & 2.85 & 1.17 \\
\hline Deceive professors about study problems & 1.95 & 1.09 \\
\hline Ask professors for preferential treatment & 1.63 & 0.95 \\
\hline
\end{tabular}

Sample size is 2003

proctors) during the USE, $21 \%$ some wrongdoing in the university admission process (e.g., cases of admission commissions, instances of preferential admissions). Reportedly, the incidence of bribery at universities after admission appears to be less of an issue. Concerning the use of informal practices by respondents while studying, by far the most popular practice is partial plagiarism when writing papers, followed by cheat sheets and copying from others at exams. The least common form of academic dishonesty is asking professors for preferential treatment (e.g., easing requirements, exemption from examinations, etc.).

Item non-response is low in our data. In about $4 \%$ of the observations, the students' year of birth is missing. Non-response in other demographic, socioeconomic, or individual characteristics is even rarer. About $3 \%$ of the students do not reveal their own informal practices (concerning the question "How often do you use the following practices...?") and whether they encountered bribery at the university. In our treat- 
ment evaluation, observations with missing values in the covariates are kept in the data, based on adding dummy variables indicating missing values in covariates to the set of control variables and replacing missing values in those covariates by zeros. This approach permits distinguishing selectivity due to non-response, which is captured by the missing dummies, from the influence of truly zero (rather than missing) covariate values.

\section{Methods}

We evaluate the effects of the anti-corruption information materials on the outcomes of interest based on two approaches. First, we take mean differences in outcomes between each of the treatment groups and the control group. This yields unbiased estimates of the treatment effects if randomization was successful, meaning that any observed and unobserved pre-treatment characteristics are comparable across the treatment groups. Although the observed pre-treatment covariates are generally well balanced in the sample, a few minor differences are still present. As a robustness check, our second approach controls for observed covariates potentially confounding the treatment-outcome association in a flexible functional way. This allows interaction and higher-order terms of covariates to enter both the treatment and outcome equations.

To this end, we apply the method of Belloni et al. (2014) to select confounders as well as nonlinear functions thereof based on LASSO regression, see Tibshirani (1996), a machine learning approach permitting variable selection in high-dimensional data. More concisely, this so-called post-double-selection method relies on a two-step, LASSO-based variable selection of control variables that are either predictive for the treatment or the outcome (or both). Thereafter, the treatment effects of interest are estimated by an OLS regression of the outcome on the treatment indicators and the selected controls. In our study, we generated higher-order terms up to the third order for non-binary covariates as well as interaction terms up to the second order using the "Generate.Powers" command in the "LARF" package by An and Wan (2016) for the statistical software "R". We added these terms to the list of potential controls for the two-step LASSO procedure and estimated the treatment effects by the "rlassoEffects" command in the R package "hdm" of Spindler et al. (2016) with "double selection" as method (and otherwise using the command's default options).

Our investigation goes beyond the analysis of treatment effects in the full sample and explores effect heterogeneity across subgroups. We opted for a data-driven rather than ad hoc approach for analyzing heterogeneity in an "honest" way, preventing inferential multiple testing issues related to "snooping" for subgroups with significant effects. This technique builds on a modification of regression trees, yet another machine learning approach, see Breiman et al. (1984). While the regression tree method partitions the sample as a function of the covariate space in a way that minimizes the sum of squared residuals when predicting the outcome, ${ }^{13}$ the causal

\footnotetext{
13 As pointed out by Lehrer and Xie (2018), minimizing the (unweighted) sum of squared residuals implicitly assumes homoskedastic errors.
} 
tree approach by Athey and Imbens (2016) used in our analysis recursively searchers for sample splits that maximizes effect heterogeneity across subgroups defined upon the splits.

Specifically, we use the "causalTree" package by Athey et al. (2016) for finding covariates and their values to split our sample on. To this end, we apply so-called honest estimation that randomly picks half of the sample for subgroup partitioning ("training data") and uses the other half ("test data") for estimating treatment effects within the defined subgroups. This sample-splitting approach avoids the aforementioned inference problems of snooping for significant effects. ${ }^{14}$ Since our analysis considers more than one treatment and several outcomes, honest splitting is conducted separately for each treatment-outcome combination, resulting in 124 regression trees. We find the most frequent predictors (and their levels) among those suggested by the recursive partitioning algorithm for the first-level (primary) splitting. In the next step, we generate binary indicators for the most important predictors and use them for splitting the total of our test data. In the effect heterogeneity analysis, the average treatment effects are then estimated separately in each of the constructed subsamples of the test data.

As we estimate the effects of each intervention on a range of outcome variables, a further concern are multiple hypothesis testing issues, implying spurious statistical significance of actually nonexisting effects. This problem arises when applying a certain significance level to each hypothesis test separately, such that the expected number of incorrect rejections of zero effects increases in the number of tests conducted. We therefore also consider joint hypothesis tests for treatment effects on groups of outcomes defined upon specific survey questions. To this end, we employ the procedure by Ludwig et al. (2017), which is based on predicting the treatment by the total of outcome variables using machine learning.

For testing, we split the data into a training and a test sample. In the training sample, we run a lasso logit regression (using the "hdm" package) of the respective treatment of interest (vs. control) on the outcomes. In the test sample, the treatment is predicted based on the lasso coefficients from the training sample. These predictions are compared to the actual treatment values in the test sample in order to compute the mean squared error (MSE). We use k-fold cross-validation, such that the roles of training and test data are swapped, and estimate the MSE as the average of the MSEs in the different test data (in order to reduce the variance of MSE estimation). In a next step, we randomly relabel (or permute) the vector of treatment indicators and re-estimate the MSE using the same procedure. Repeating the permutation 999 times, we compute the p-value for the joint significance of treatment effects on the outcomes as the share of permutation-based MSEs that are lower than the MSE with the correct coding of the treatment. The intuition of the test is that if the outcomes are not associated with the treatment, relabeling the latter will not increase the MSE. If, on the other hand, there is an effect of the treatment on (at least some) outcomes, then the correct coding of the treatment should entail a smaller MSE than the permuted versions. We run the test for grouped outcomes separately for each treatment in the full sample as well as for the subgroups defined by the causal tree procedure.

\footnotetext{
14 To limit the complexity of trees, we apply cross-validation for determining the optimal number of splits. Furthermore, the minimum leaf (i.e., subgroup) size is set to 25 observations.
} 


\section{Results}

Table 2 reports the effect estimates based on taking mean differences in outcomes across treatment states in the full sample. Column 2 presents the mean outcomes in the control group. The third column contains the estimated treatment effects of the official corruption-awareness brochure, while the fourth column gives the heteroskedasticityrobust $p$ values. The estimates for the brochure developed by our team and the videos about the negative consequences of bribery and a hostile corporate raid, i.e., reiderstvo, are presented in columns 5-6, 7-8, and 9-10, respectively.

Looking at the control means, we find that informal practices were judged to be quite common. The use of cheat sheets during exams, partial plagiarism from the internet, and copying from other students during exams were thought to occur rather often, as their control means are close to 4 on a scale from 1 (never) to 5 (systematically). Furthermore, corruption was predominantly seen as a "crime" and "evil" and much less as a "necessity". Interestingly, students perceived corruption's impact on an aggregate level (i.e., its effects on the Russian economy, politics, education and health systems, and police) more negatively, on average, than on a personal level (i.e., on students' career opportunities, quality of life, education, health, and safety). As far as participation in future corruption-awareness activities is concerned, students expressed very little interest: only 5\% agreed to join a round table discussion about corruption, and $12 \%$ were willing to take part in another survey about corruption one year later.

Considering treatment effects, the official brochure increased the perceived frequency of students copying from others during examinations (significant at the $10 \%$ level) and tolerance for informal academic practices in several cases: when a course was considered "useless", when students worked, and when it was hard to learn the material (the effects are statistically significant at the 1,10, and 5\% levels, respectively). Also, students who received the official brochure were more likely to agree to corruption being a means of income (significant at the 5\% level) and to more positively see corruption in the context of the Russian health system and police (significant at the $5 \%$ and $10 \%$ levels, respectively). The tailored brochure increased the perceived frequency of plagiarizing from the internet (significant at the 1\% level) and decreased the incidence of never accepting academic cheating (significant at the $10 \%$ level). The anti-bribery video slightly increased the reported frequency of submitting papers downloaded from the internet (significant at the $10 \%$ level). Almost all interventions seemed to lower students' interest in the round table and the later survey by about 2-3 percentage points, although only the effects of the official brochure and the antibribery video were statistically significant (at the 5-10\% level). Overall, only few of the all in all 124 hypothesis tests were statistically significant, making it likely that they are in fact spurious.

As a robustness check, we considered the post-double-selection method by Belloni et al. (2014) to control any covariate imbalances when estimating treatment effects. As shown in Table A2 in Online Appendix A, the effects are very similar in terms of size and significance to the mean difference estimates. Thus, our results are not sensitive to the inclusion of observed control variables. To account for inference issues related to multiple hypothesis testing with a large number of individual outcomes, we applied the 


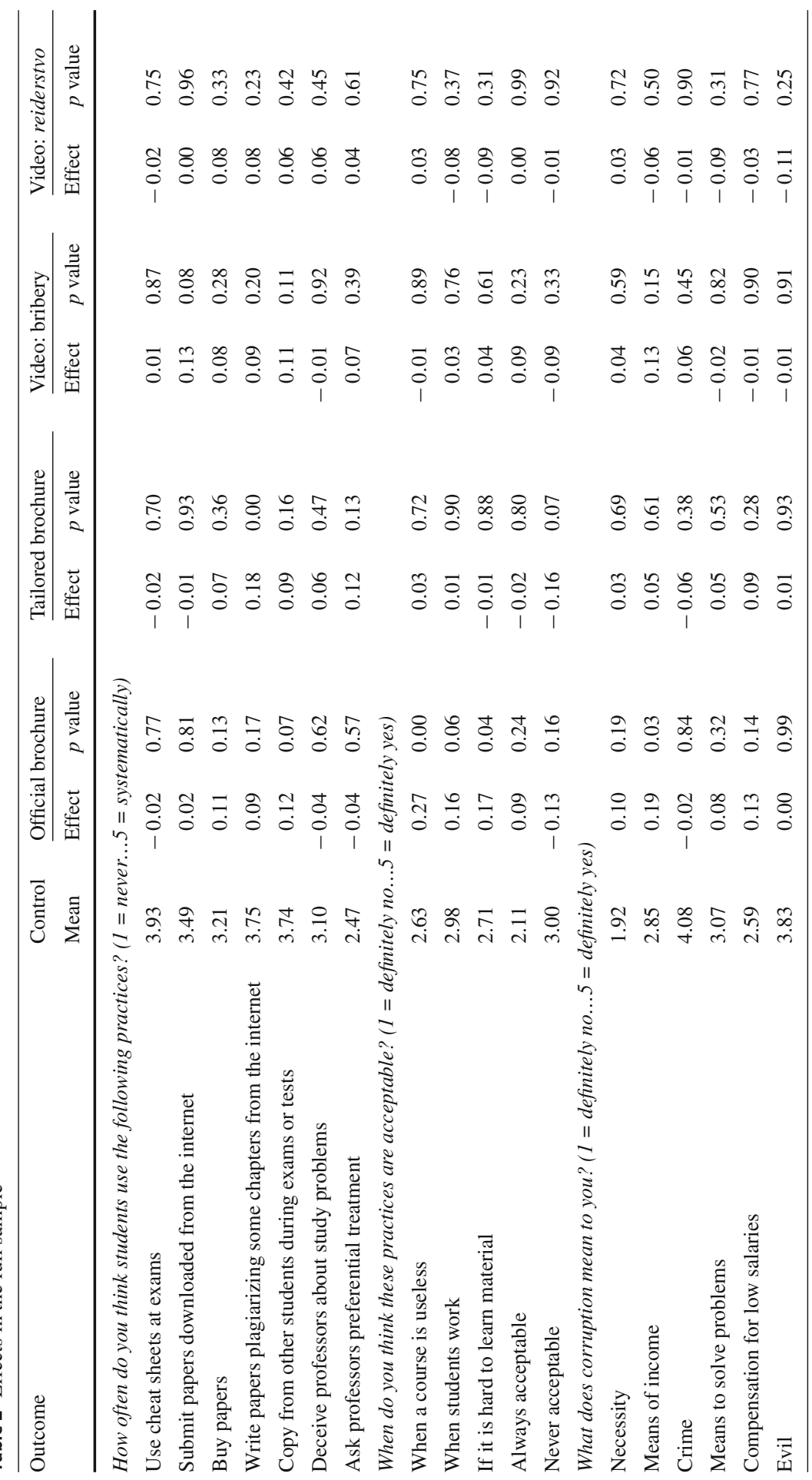




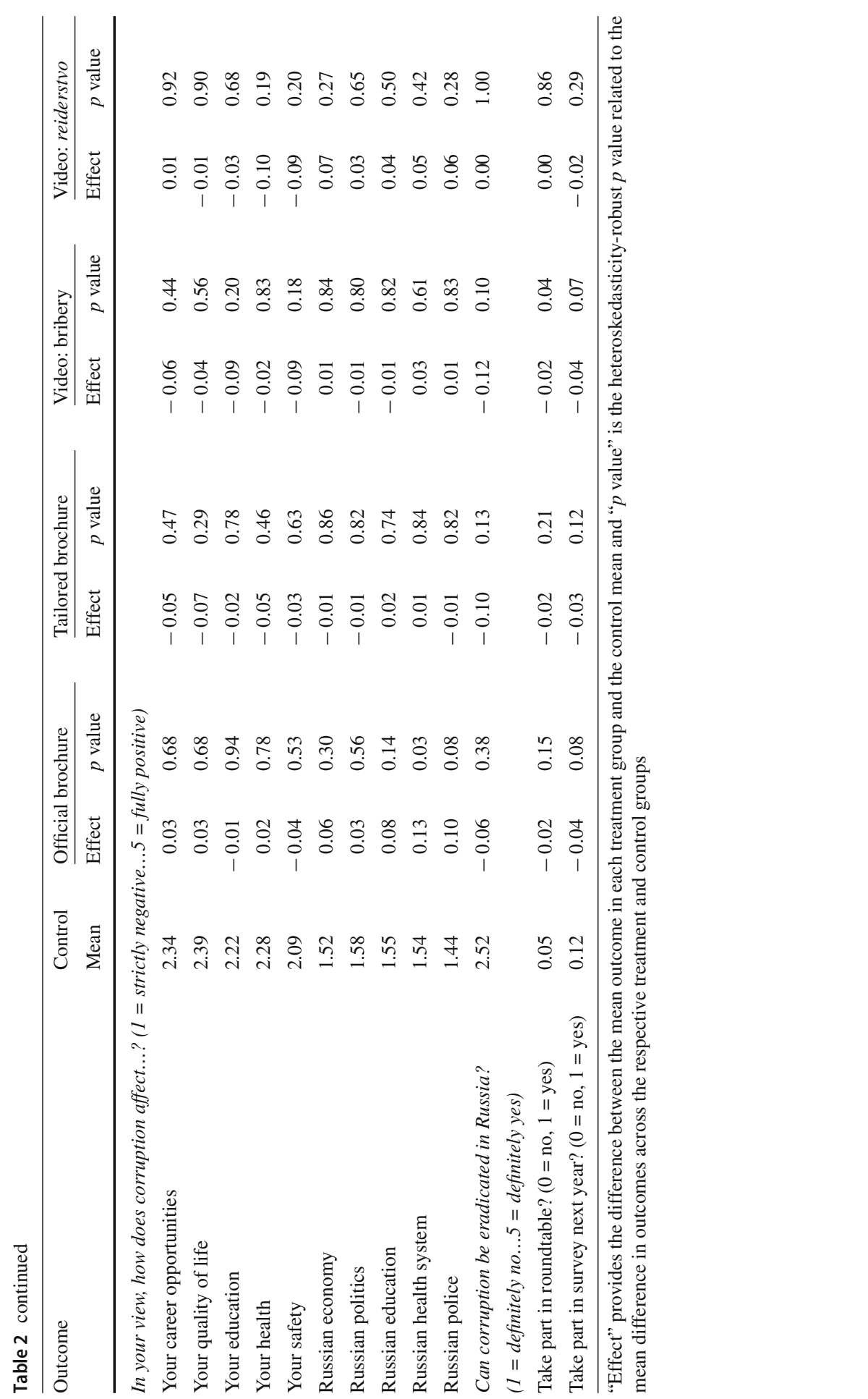


Table 3 Multiple outcomes test in full sample

\begin{tabular}{|c|c|c|c|c|}
\hline Question group & $\begin{array}{l}\text { Official } \\
\text { brochure }\end{array}$ & $\begin{array}{l}\text { Tailored } \\
\text { brochure }\end{array}$ & $\begin{array}{l}\text { Video: } \\
\text { bribery }\end{array}$ & $\begin{array}{l}\text { Video: } \\
\text { reiderstvo }\end{array}$ \\
\hline $\begin{array}{l}\text { How often do you think students use the } \\
\text { following [corrupt] practices? }\end{array}$ & 0.97 & 0.17 & 0.69 & 0.33 \\
\hline $\begin{array}{l}\text { When do you think these [corrupt] practices } \\
\text { are acceptable? }\end{array}$ & 0.30 & 0.77 & 0.58 & 0.40 \\
\hline What does corruption mean to you? & 0.94 & 0.55 & 0.50 & 0.88 \\
\hline $\begin{array}{l}\text { In your view, how does corruption affect } \\
\text { aspects of your life? }\end{array}$ & 0.61 & 0.65 & 0.69 & 0.51 \\
\hline $\begin{array}{l}\text { In your view, how does corruption affect } \\
\text { public spheres in Russia? }\end{array}$ & 0.97 & 0.76 & 0.65 & 0.45 \\
\hline Interest in anti-corruption activities & 0.91 & 0.95 & 0.65 & 0.94 \\
\hline
\end{tabular}

The $p$ values of the joint significance tests are presented

test of Ludwig et al. (2017) to verify whether treatment effects are jointly significant for groups of outcomes defined by the questions asked in the survey. The $p$ values from the tests presented in Table 3 indicate that the multiple outcome tests fail to reject the null hypotheses of no treatment effects in the considered outcome groups. This supports our suspicion that the few statistically significant effects on individual outcomes are spurious, which implies that the treatments were not effective in the full sample.

\section{Heterogeneity of effects}

Applying recursive partitioning algorithm of Athey and Imbens (2016) to our data indicates that treatment effects differ most commonly across students who never, seldom, or sometimes wrote papers by plagiarizing from the internet versus those who did it often or systematically (10 primary-level splits). ${ }^{15}$ Table 4 reports the joint significance tests of Ludwig et al. (2017) for groups of outcomes (based on specific survey questions) in these subsamples. To this end, only the test sample of the Athey and Imbens (2016) procedure, consisting of 1002 observations, is used (and the same applies to estimating effects on individual outcomes further below) in order to obtain "honest" inference, see the discussion in Sect. 3. Among the 463 students plagiarizing more often, we found a jointly statistically significant (at the 5\% level) effect of the tailored brochure on the outcomes of question "In your view, how does corruption affect aspects of your life?" (Table 4, Panel A). Among the 513 students plagiarizing never, seldom, or sometimes, the tailored brochure had a significant (at the $10 \%$ level) effect on the outcomes related to students' interest in anti-corruption activities. The anti-bribery video statistically significantly (at the 5\% level) affected outcomes of the question "In your view, how does corruption affect public spheres in Russia?" (Table 4, Panel B). However, we emphasize that these findings must be interpreted

\footnotetext{
15 There are in total 124 treatment-outcome test combinations. Given our specification of recursive partitioning, splits are, however, not found for some combinations, which results in 95 primary-level splits.
} 


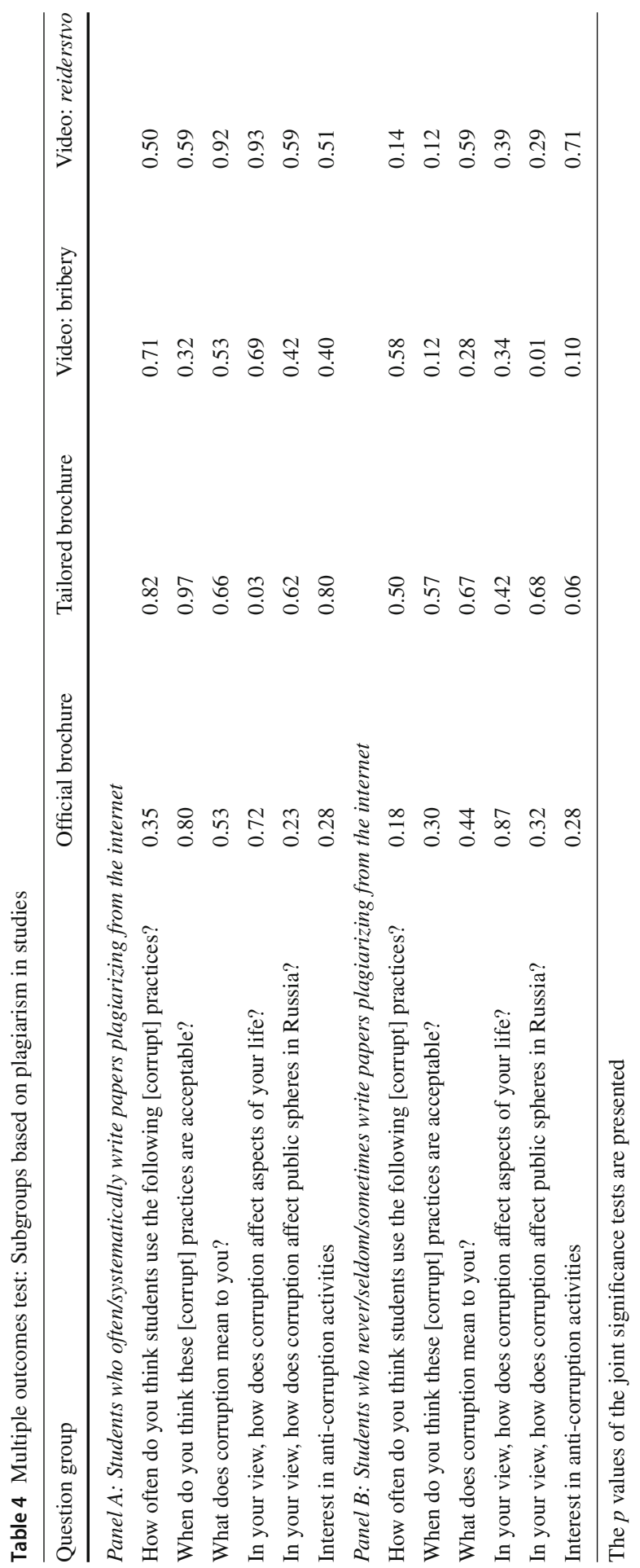


with caution, in the light that testing effects on several groups of outcomes entails yet another multiple testing issue. Even within subgroups, the effects might in fact be spurious.

Bearing such issues of multiple hypothesis testing in mind, Tables 5 and 6 present the results for individual outcomes within groups of students more and less frequently plagiarizing, respectively. When considering mean outcomes under non-treatment in both groups, those plagiarizing reported a higher frequency of various informal practices among students, showed more acceptance of dishonesty, and were more skeptic about the possibility of eradicating corruption in Russia. ${ }^{16}$ Concerning treatment effects, the tailored brochure apparently impacted both groups more importantly than other interventions, yielding a larger number of statistically significant effects. The video treatments seemed to be least effective in changing students' attitudes.

Plagiarizing students tended to react to the treatments as one would expect. Brochures seemed (if anything) to negatively affect students' perception of the impact of corruption on all the listed aspects of personal life, including career, quality of life, education, health, and safety. However, only the first three of these outcomes were affected statistically significantly (at the $1-10 \%$ levels). The official brochure reduced perceived frequencies of using cheat sheets at examinations, deceiving professors about study problems, and asking professors for preferential treatment (significant at the $5-10 \%$ levels). The tailored brochure seemed to lower the reported use of cheat sheets and buying papers (statistically significant at the $10 \%$ level), as well as the acceptance of informal practices (statistically significant only for "always acceptable"). The reiderestvo video negatively affected the view of informal practices being "always acceptable" or acceptable when the course material is hard to learn (both statistically significant at the $10 \%$ level).

For students plagiarizing less frequently, some information materials tended to raise the reported frequency of informal practices and their acceptance, lower the belief that corruption can be eradicated in Russia, and reduce the interest in corruption-awareness activities. However, only few effects are statistically significant. For instance, the tailored brochure increased the reported frequency of informal practices such as plagiarizing from the internet, copying from others at examinations, deceiving professors about study problems, and asking them for preferential treatment (statistically significant at the $5-10 \%$ levels). The tailored brochure also led to a more positive perception of the impact of corruption on education and the health system in Russia, while it negatively affected students' interest in the round table and the next survey (all significant at the $5 \%$ level). Lastly, the official brochure increased the view that informal practices are always acceptable or acceptable when the course was considered "useless" (statistically significant at the $5 \%$ level).

Although not suggested by the recursive partitioning algorithm, we also consider effect heterogeneities across gender [as important gender differences emerge in the corruption literature, see for example Swamy et al. (2001) and Jetter and Walker (2015)], by comparing the groups of 911 male and 1092 female students. The $p$ values of the multiple outcome tests of Ludwig et al. (2017) are presented in Online Appendix A Table A3. The tests did not point to jointly statistically significant effects for female

16 Most of these differences across subgroups are statically significant at the $5 \%$ or $10 \%$ levels. 


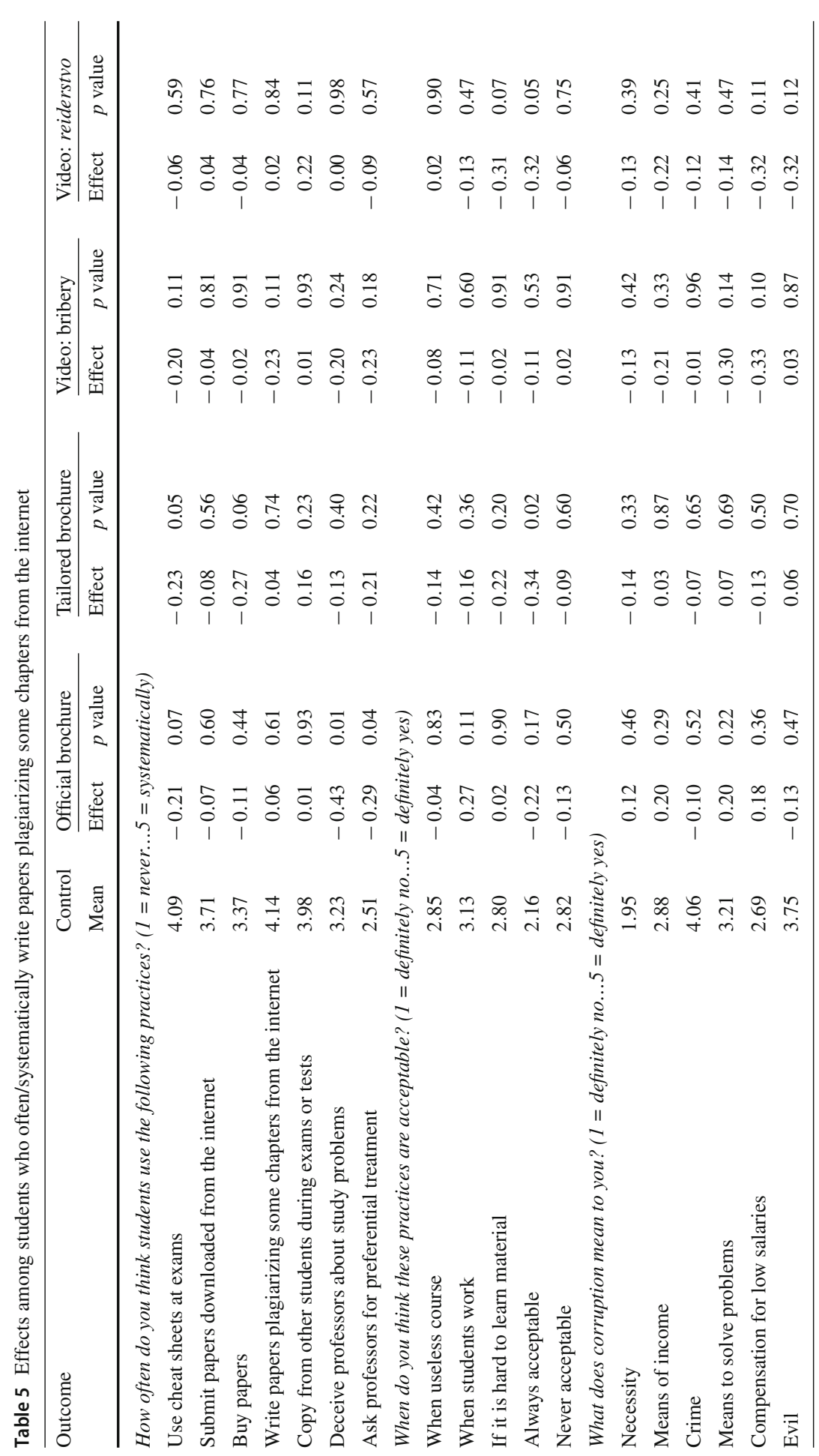




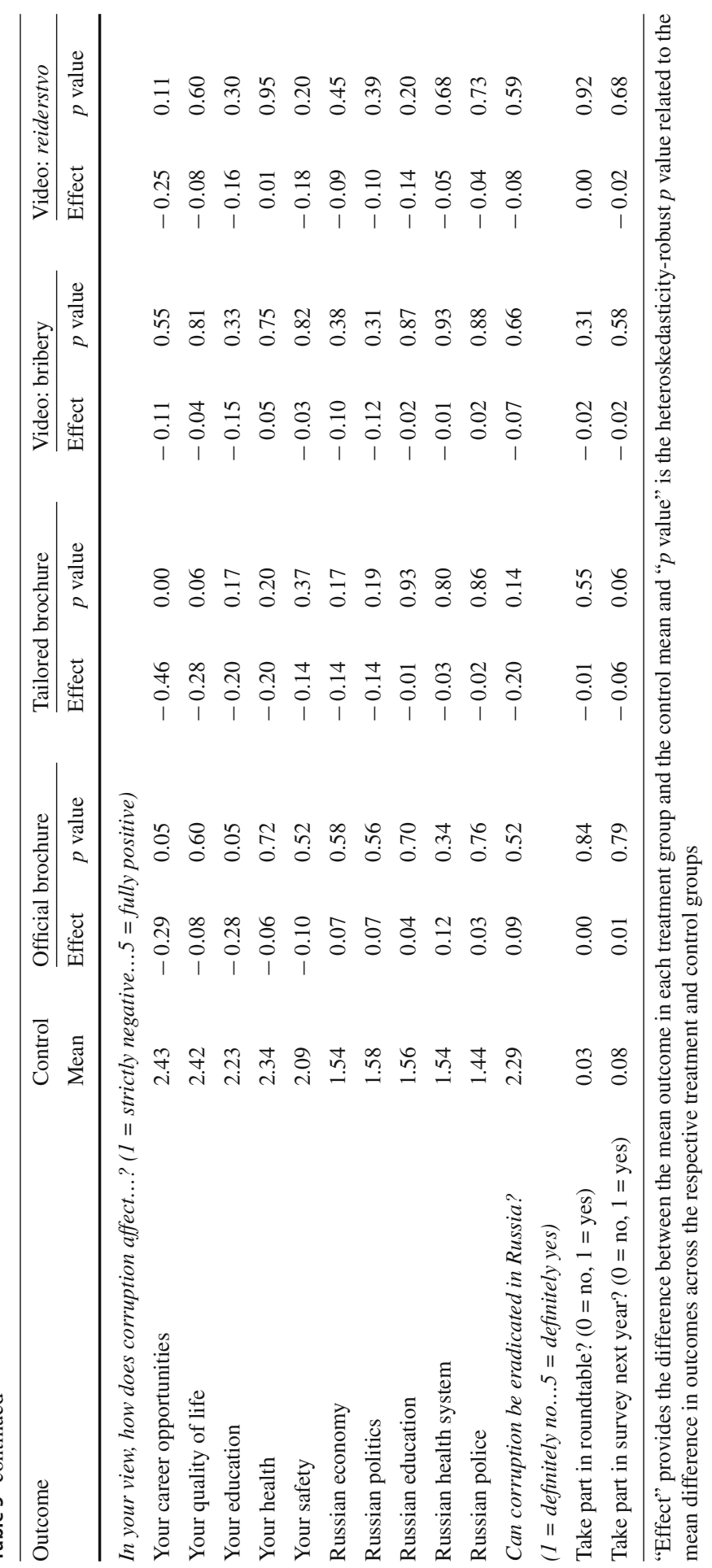




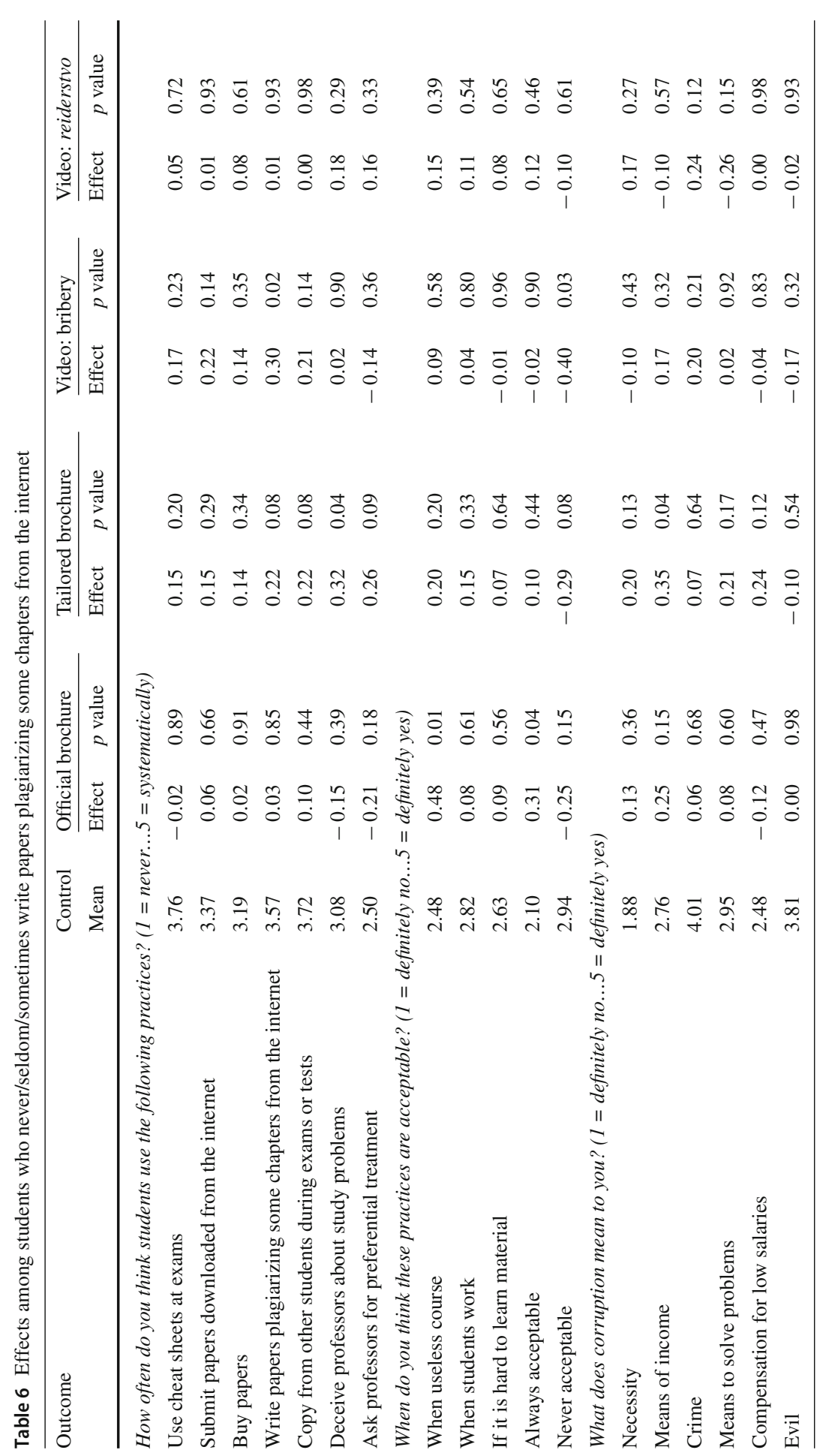




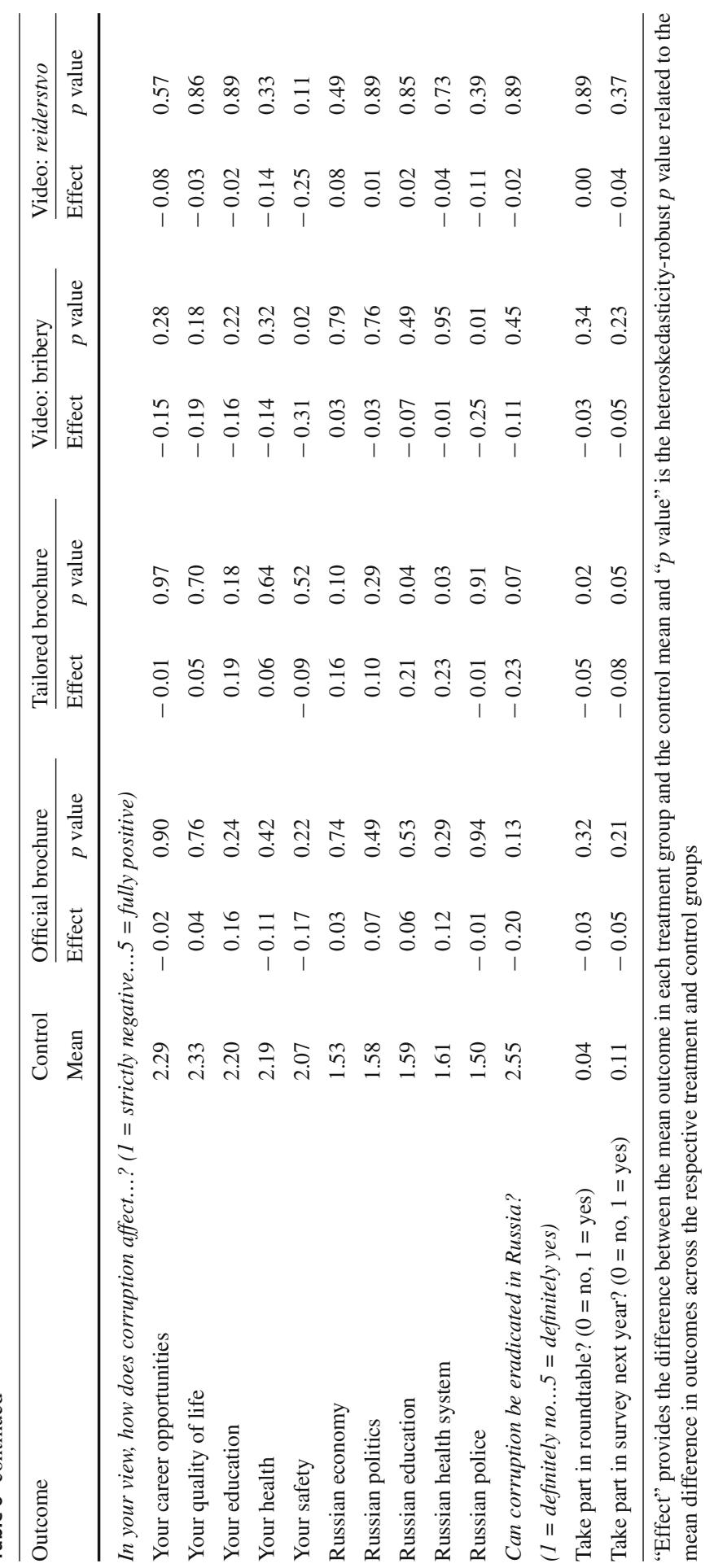


students (Panel B). Among male students (Panel A), the official brochure appeared to affect the acceptance of informal academic practices and their opinion about the impact of corruption on public spheres in Russia (significant at the 5\% level). The reiderstvo video increased the reported frequency of informal academic practices and the perceived impact of corruption on public sectors in the country (significant at the $10 \%$ level). Again, even for the male students, the number of significant effects is low and might be spurious, given that several (joint) hypotheses are tested.

Tables A4 (for males) and A5 (for females) report the effects on individual outcome variables. Considering mean outcomes in the respective control groups, females had more negative views about corruption and were more reluctant to participate in future corruption-awareness activities than males. Male students exposed to the official brochure were more tolerant toward informal academic practices, but effects were only statistically significant for the cases that the course was considered "useless" and students worked (at the 5-10\% levels). The official brochure also seemed to induce a more positive perception of corruption on the global level, particularly w.r.t. the Russian health system and police (statistically significant at the 1 and 10\% levels). Furthermore, male students were significantly (at the 10\% level) dissuaded by all the treatments (but the reiderstvo video) from participation in corruption-awareness activities, whereas females remained unaffected. Overall, with fewer significant treatment effects, female students appeared, on average, less responsive to the intervention than males.

\section{Conclusion}

In this paper, we examined the attitudes of Russian students toward dishonest academic practices and corruption and used an experimental design to investigate the short term effects of an educational campaign consisting of four distinct interventions: two brochures (one officially provided by the local authorities and one particularly tailored to students) and two videos (about bribery and hostile corporate takeovers) informing students about corruption and its negative consequences. The results suggest that various forms of academic cheating are quite common at Russian universities. At the same time, the attitudes toward corruption are generally negative among surveyed students. Corruption is believed to have particularly detrimental consequences at the aggregate (national) level, while its effects at the individual level are viewed somewhat less negatively.

While we did not find important effects of the interventions in the full sample, some results suggest that there might be heterogeneous effects across subsamples defined upon students' plagiarizing behavior and gender. However, these findings need to be interpreted with caution, as statistical significance mostly vanishes when accounting for multiple hypothesis testing. Taken at face value, one interesting aspect is that the interventions appeared to promote negative views of corruption among students who plagiarize more frequently, while they led to more tolerance or pragmatic attitudes toward academic dishonesty and corruption among students plagiarizing less frequently or not at all. Furthermore, while female students had a more negative opinion about corruption than males, they were generally less responsive to interventions. 
This suggests that such interventions may nudge the attitudes of some groups into the direction desired by the policy maker, but might produce no or even counteracting effects in other groups by increasing the awareness of corruption. Policy makers aiming to conduct large-scale anti-corruption campaigns might thus want to scrutinize the possibility of heterogeneous effects to appropriately target specific subgroups. This can admittedly be difficult in practice, as relevant subgroups may not be easily identified (e.g., plagiarizing vs. non-plagiarizing students) or addressed by distinct interventions.

Our study, which applies the method of Athey and Imbens (2016) to analyze effect heterogeneity, is part of a growing literature aiming at assessing heterogeneous effects across observed covariates using machine learning. For further reference, see, for instance, Wager and Athey (2018), Athey et al. (2019), and Lechner (2019), who develop and refine heterogeneity analysis based on the related method of random forests. The latter goes back to Breiman (2001) and averages over trees in resampled data rather than relying on a single tree. Random forest-based approaches permit estimating the so-called individualized treatment effect, which corresponds to the expected effect for a particular individual given her specific covariate values. Powers et al. (2018) and Knaus et al. (2018) provide surveys on further machine learning methods for assessing effect heterogeneity and investigate their finite sample behavior by means of simulations. See also Knaus et al. (2017) for an application in the field of labor market policy evaluation.

Acknowledgements This study was conducted with financial support provided by the Center for Governance and Culture in Europe at the University of St. Gallen (HSG), Switzerland. The sponsor influenced neither the research design nor the interpretation of the results.

\section{References}

Altbach PG (2016) Global perspectives on higher education. John Hopkins University Press, Baltimore An W, Wan X (2016) R: local average response functions for instrumental variable estimation of treatment effects. https://cran.r-project.org/web/packages/LARF/. Accessed June 2017

Armantier O, Boly A (2011) A controlled field experiment on corruption. Eur Econ Rev 55(8):1072-1082

Armantier O, Boly A (2013) Comparing corruption in the laboratory and in the field in Burkina Faso and in Canada. Econ J 123(573):1168-1187

Athey S, Imbens G (2016) Recursive partitioning for heterogeneous causal effects. Proc Natl Acad Sci 113(27):7353-7360

Athey S, Imbens G, Kong Y, Ramachandra V (2016) An introduction to recursive partitioning for heterogeneous causal effects estimation using causalTree package. https://github.com/susanathey/causalTree. Accessed June 2017

Athey S, Tibshirani J, Wager S (2019) Generalized random forests. Ann Stat 47:1148-1178

Barr A, Serra D (2010) Corruption and culture: an experimental analysis. J Public Econ 94(11):862-869

Belloni A, Chernozhukov V, Hansen C (2014) Inference on treatment effects after selection among highdimensional controls. Rev Econ Stud 81(2):608-650

Breiman L (2001) Random forests. Mach Learn 45:5-32

Breiman L, Friedman J, Olshen R, Stone C (1984) Classification and regression trees. Wadsworth, Belmont

Cantoni D, Yang DY, Yuchtman N, Zhang YJ (2019) Protests as strategic games: experimental evidence from Hong Kong's antiauthoritarian movement. Q J Econ 134(2):1021-1077

Corbacho A, Gingerich DW, Oliveros V, Ruiz-Vega M (2016) Corruption as a self-fulfilling prophecy: evidence from a survey experiment in Costa Rica. Am J Polit Sci 60(4):1077-1092

Currie J, Kleven H, Zwiers E (2019) Technology and big data are changing economics: mining text to track methods. Working paper, Princeton University 
Denisova-Schmidt E (2017) The challenges of academic integrity in higher education: current trends and outlook. CIHE perspectives, vol 5. Boston College, Boston

Denisova-Schmidt E (2019) Corruption in higher education. In: Teixeira N, Shin J-C (eds) Encyclopedia of international higher education systems and institutions. Springer, Berlin

Denisova-Schmidt E, de Wit H (2017) The global challenge of corruption in higher education. IAU Horizons 22(1):28-29

Denisova-Schmidt E, Huber M, Leontyeva E (2016) Do anti-corruption educational campaigns reach students? Some evidence from Russia and Ukraine. Educ Stud Mosc 1:61-83

Denisova-Schmidt E, Huber M, Prytula Y (2015) An experimental evaluation of an anti-corruption intervention among Ukrainian university students. Eurasian Geogr Econ 56(6):713-734

Dimant E, Tosato G (2017) Causes and effects of corruption: what has past decade's research taught us? A survey. J Econ Surv 32:335-356

Dollar D, Fisman R, Gatti R (2001) Are women really the "fairer" sex? Corruption and women in government. J Econ Behav Organ 46(4):423-429

Federal State Statistics Service (2016) Chislennost' naselenia Rossiyskoy Federatsiy po municipalnim obrazovaniyam (The population of the Russian Federation by municipalities). Online bulletin, Federal State Statistics Service. http://www.gks.ru/wps/wcm/connect/rosstat_main/rosstat/ru/statistics/ publications/catalog/afc8ea004d56a39ab251f2bafc3a6fce. Accessed June 2017

Findley M, Nielson D, Sharman J (2014) Global shell games. Cambridge University Press, Cambridge

Frank B, Lambsdorff JG, Boehm F (2011) Gender and corruption: lessons from laboratory corruption experiments. Eur J Dev Res 23(1):59-71

Holmes L (2015) Corruption: a very short introduction. Oxford University Press, Oxford

Jetter M, Walker JK (2015) Good girl, bad boy: corrupt behavior in professional tennis. Working paper, Center for Research in Economics and Finance (CIEF)

John LK, Loewenstein G, Rick SI (2014) Cheating more for less: upward social comparisons motivate the poorly compensated to cheat. Organ Behav Hum Decis Process 123(2):101-109

Kasamara V, Sorokina A (2017) Rebuilt empire or new collapse? Geopolitical visions of Russian students. Eur Asia Stud 69(2):262-283

Klemenčič M (2014) Student power in a global perspective and contemporary trends in student organising. Stud High Educ 39(3):396-411

Knaus M, Lechner M, Strittmatter A (2017) Heterogeneous employment effects of job search programmes: a machine learning approach. CEPR Discussion Paper No. DP12224

Knaus M, Lechner M, Strittmatter A (2018) Machine learning estimation of heterogeneous causal effects: empirical monte carlo evidence. Working paper, University of St. Gallen

Korostelev A, Romenskiy V, Sagieva K. (Hosts) (2017) Progulka rasserzhennyh shkol'nikov: kak pokolenie YouTube vyshlo na ulicu i kak ego nakazhut (Angry pupils' walk: how the YouTube generation went out into the streets and how it will be punished). In Pushkarev V, Yapparova L, Borzunova M, Alexandrov A, Zhelvnov A, Ruzavin P et al (eds) Zdes' i sejchas. Vechernee shou [Here and now. The evening show]. Dozhd', Moscow, Russia. https://tvrain.ru/teleshow/vechernee_shou/on_vam_ ne_dimon-430761/.Accessed June 2017

Lechner M (2019) Modified causal forests for estimating heterogeneous causal effects. CEPR Discussion Paper No. DP13430

Lehrer SF, Pohl RV, Song K (2016) Targeting policies: multiple testing and distributional treatment effects. NBER Working Paper No. 22950

Lehrer SF, Xie T (2018) The bigger picture: combining econometrics with analytics improve forecasts of movie success. NBER Working Paper No. 24755

Ludwig J, Mullainathan S, Spiess J (2017) Machine learning tests for effects on multiple outcomes. Unpublished paper. https://scholar.harvard.edu/spiess/publications/machine-learning-tests-effectsmultiple-outcomes

Nosek BA, Ebersole CR, DeHaven AC, Mellor DT (2018) The preregistration revolution. Proc Natl Acad Sci 115:2600-2606

Obrazovanie v Rossiiskoi Federatsii (2014) [Education in the Russian Federation: 2014] (2014). Statistical compilation, National Research Institute "Higher School of Economics", Moscow, Russia

Powers S, Qian J, Jung K, Schuler A, Shah NH, Hastie T, Tibshirani R (2018) Some methods for heterogeneous treatment effect estimation in high dimensions. Stat Med 37:1767-1787

Rivas MF (2013) An experiment on corruption and gender. Bull Econ Res 65(1):10-42 
Romano JP, Wolf M (2005) Exact and approximate stepdown methods for multiple hypothesis testing. J Am Stat Assoc 100:94-108

Romano JP, Wolf M (2016) Efficient computation of adjusted p-values for resampling-based stepdown multiple testing. Stat Probab Lett 113:38-40

Serra D, Wantchekon L (2012) New advances in experimental research on corruption. Emerald, Bingley

Spindler M, Chernozhukov V, Hansen C (2016) R: high-dimensional metrics. https://cran.r-project.org/ web/packages/hdm/. Accessed June 2017

Swamy A, Knack S, Lee Y, Azfar O (2001) Gender and corruption. J Dev Econ 64(1):25-55

Tibshirani R (1996) Regresson shrinkage and selection via the lasso. J R Stat Soc 58:267-288

Transparency International Russia (2015a) Episode 1: Bribe. YouTube video. https://www.youtube.com/ watch?v=zGeworhwEFo. Accessed July 2017

Transparency International Russia (2015b) Episode 3: Corruption corporate raid. YouTube video. https:// www.youtube.com/watch?v=4aTjUyX67xc. Accessed July 2017

Volkov D (2017) Effekt ot filma "On vam ne Dimon" pochti proshel [The effect of the film "He is not Dimon to you" has almost passed]. Gazeta.ru. https://www.gazeta.ru/comments/2017/05/25_a_10691315. shtml. Accessed June 2017

Wager S, Athey S (2018) Estimation and inference of heterogeneous treatment effects using random forests. J Am Stat Assoc 113:1228-1242

Publisher's Note Springer Nature remains neutral with regard to jurisdictional claims in published maps and institutional affiliations.

\title{
Affiliations
}

\section{Elena Denisova-Schmidtt ${ }^{1,4}$ - Martin Huber ${ }^{2}$. Elvira Leontyeva ${ }^{3}$. Anna Solovyeva ${ }^{2}$}

\author{
Martin Huber \\ martin.huber@unifr.ch \\ Elvira Leontyeva \\ 000645@pnu.edu.ru
}

Anna Solovyeva

anna.solovyeva@unifr.ch

1 School of Humanities and Social Sciences, University of St.Gallen (HSG), Müller-Friedberg-Strasse 8, 9000 St. Gallen, Switzerland

2 Department of Economics, University of Fribourg, Bd. de Pérolles 90, 1700 Fribourg, Switzerland

3 School of Social Studies and Humanities, Pacific National University, ul. Tikhookeanskaya, 136, Khabarovsk, Russia 680035

4 Center for International Higher Education, Boston College, Chestnut Hill, USA 